\title{
Arc Interference Behavior during Twin Wire Gas Metal Arc Welding Process
}

\author{
Dingjian Ye, Xueming Hua, and Yixiong Wu \\ Shanghai Key Laboratory of Materials Laser Processing and Modification, Shanghai Jiao Tong University, Shanghai 200240, China \\ Correspondence should be addressed to Dingjian Ye; yedingjian@sjtu.edu.cn
}

Received 16 August 2013; Revised 11 November 2013; Accepted 11 November 2013

Academic Editor: Caner Simsir

Copyright (C) 2013 Dingjian Ye et al. This is an open access article distributed under the Creative Commons Attribution License, which permits unrestricted use, distribution, and reproduction in any medium, provided the original work is properly cited.

\begin{abstract}
In order to study arc interference behavior during twin wire gas metal arc welding process, the synchronous acquisition system has been established to acquire instantaneous information of arc profile including dynamic arc length variation as well as relative voltage and current signals. The results show that after trailing arc (T-arc) is added to the middle arc (M-arc) in a stable welding process, the current of $\mathrm{M}$ arc remains unchanged while the agitation increases; the voltage of $\mathrm{M}$ arc has an obvious increase; the shape of $M$ arc changes, with increasing width, length, and area; the transfer frequency of $M$ arc droplet increases and the droplet itself becomes smaller. The wire extension length of twin arc turns out to be shorter than that of single arc welding.
\end{abstract}

\section{Introduction}

In recent years, numbers of researches have been focused on studying welding materials, welding technology, and welding equipment, especially the multiwire welding, to enhance the welding productivity $[1,2]$. In twinwire or even multiwire MIG welding, the purpose is to increase the welding speed while the line energy remains constant. As several wires are melting at the same time, the deposition rate undoubtedly turns out to be higher than a single one.

As it can improve welding productivity and ameliorate the welding formation, twin wire welding has attracted extensive attention. Nowadays, the most frequently used twin wire welding mainly includes twin wire gas metal arc welding [3], TANDEM twin wire welding [4], and submerged arc welding (SAW) [5]. The primary problem in twin wire welding process is the interference between the two arcs which directly affects the welding quality [6]. The interference between the two arcs induces the variance of respective arc morphology which further leads to the change in thermal space allocation. In order to obtain ideal welding effect, pulse power supply is widely used. The control setups for adjusting two welding power supplies use three modes: synchronous, alternating, and random modes. It can control welding arc and relative timing relations of short circuit in order to reduce the mutual interference [7].
By far, researches about-arc interruption phenomenon of twin wire mostly focus on the P-GMAW TANDEM welding method. Ueyama and Ohnawa [8] utilized the pulse control method, while the phenomenon of arc interference and voltage instability still remained severe. Scotti et al. [7] took advantage of high-speed photography to analyze the two melting droplet transfer and arc behavior under different conditions by varying current level and different phase. Ueyama et al. [9] also found that the welding torch structure had an influence on welding formation during highspeed pulse TANDEM welding process. The result showed that using specifically constructed welding torches could obtain the stable burning arc, increase the welding speed and obtain better welding formation. Ueyama et al. [4] studied the effect of wire spacing and the shielding gas composition on arc interference during pulse TANDEM welding process. Yudodibroto et al. [10] came out with an index for assessment of TANDEM welding arc stability through statistics and calculation of welding current and voltage analysis. Ueyama et al. [11] showed how the state of the welding pool surface had an effect on the voltage of the abnormal arc by employing the minimum voltage principle.

In this paper, the arc interference of high strength low alloy steel in twin wire GMAW was investigated by observing the arc profile variation as well as measuring the electric signals variation. 


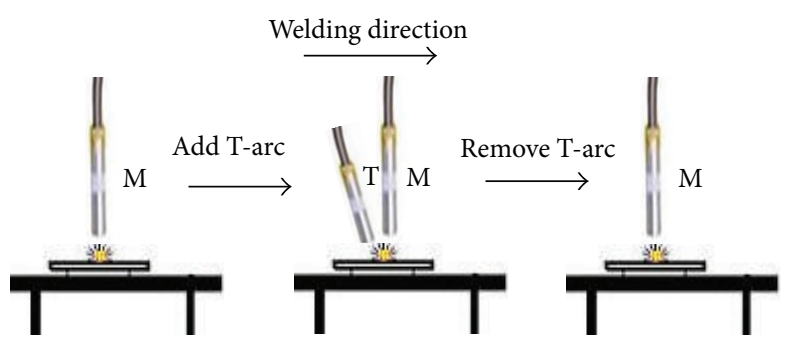

FIGURE 1: Experimental schematic model.

\section{Experimental Procedure}

During the experiment, the first wire is defined as M-arc along the welding direction; the following wire is defined as T-arc. The double arc welding is realized by adding Tarc to the system after $\mathrm{M}$-arc is steadily burning. After $\mathrm{M}$ - and T-arcs steadily burn together for two seconds, Tarc is removed from the system. The arc interference is analyzed mainly in four aspects: the electrical signal, the arc shape, the droplet transfer frequency, and the wire extension length. The experimental process is shown in Figure 1. Highspeed camera system and electrical signal acquisition system are employed to monitor the process so as to obtain the interference information. M-arc profile is taken by highspeed photography system. The whole experimental system of high-speed twin wire welding is displayed in Figure 2.

2.1. Materials. The sample employed in welding tests is high strength low alloy steel with the thickness of $15 \mathrm{~mm}$. The chemical composition of the material is shown in Tables 1 and 2. The filler material used in this research is a super cored 70MXH welding wire with the diameter of $1.6 \mathrm{~mm}$. The shielding gas used is pure $\mathrm{CO}_{2}$, which is widely used in shipbuilding.

2.2. Welding Equipment. Experimental equipment system consisted of Panasonic YD-500GR3 welding power source, electrical signal acquisition card, high-speed camera system, and so forth.

2.3. Welding Parameters. The double electrode is all positive (welding torch is adjacent to the anode). The torch distance as well as the distance between nozzle and the base metal are both $20 \mathrm{~mm}$. And the intersection angle between two adjacent torches is $10^{\circ}$. The flat welding is performed with $\mathrm{CO}_{2}$ shielding gas flow of $20 \mathrm{~L} / \mathrm{min}$ and the welding speed of $500 \mathrm{~mm} / \mathrm{min}$. The current and voltage of $\mathrm{M}$ - and T-arcs are $250 \mathrm{~A} / 27.5 \mathrm{~V}$ and $200 \mathrm{~A} / 25 \mathrm{~V}$, respectively.

\section{Results and Discussion}

3.1. Analysis of Signals Waveform of Twin Wire GMAW. The double arc welding is realized by adding T-arc to the system after M-arc is steadily burning. In this process, the current and voltage of $\mathrm{M}$ - and T-arcs are measured during the experiment, which are shown in Figure 3. The diagram
TABLE 1: Chemical composition of base metal.

\begin{tabular}{lcccccccc}
\hline Steel no. & $\begin{array}{c}\mathrm{C} \\
(\%)\end{array}$ & $\begin{array}{c}\mathrm{Si} \\
(\%)\end{array}$ & $\begin{array}{c}\mathrm{Mn} \\
(\%)\end{array}$ & $\begin{array}{c}\mathrm{P} \\
(\%)\end{array}$ & $\begin{array}{c}\mathrm{S} \\
(\%)\end{array}$ & $\begin{array}{c}\mathrm{Cr} \\
(\%)\end{array}$ & $\begin{array}{c}\mathrm{Ni} \\
(\%)\end{array}$ & $\begin{array}{c}\mathrm{Cu} \\
(\%)\end{array}$ \\
\hline AB-A & 0.15 & 0.78 & 0.08 & 0.19 & 0.2 & 0.03 & 0.01 & 0.02 \\
\hline
\end{tabular}

TABLE 2: Chemical composition of super cored 70MXH welding wire.

\begin{tabular}{lcccccccc}
\hline Steel no. & $\begin{array}{c}\mathrm{C} \\
(\%)\end{array}$ & $\begin{array}{c}\mathrm{Si} \\
(\%)\end{array}$ & $\begin{array}{c}\mathrm{Mn} \\
(\%)\end{array}$ & $\begin{array}{c}\mathrm{P} \\
(\%)\end{array}$ & $\begin{array}{c}\mathrm{S} \\
(\%)\end{array}$ & $\begin{array}{c}\mathrm{Cr} \\
(\%)\end{array}$ & $\begin{array}{c}\mathrm{Ni} \\
(\%)\end{array}$ & $\begin{array}{c}\mathrm{Cu} \\
(\%)\end{array}$ \\
\hline AB-A & 0.05 & 0.55 & 1.65 & - & - & - & - & - \\
\hline
\end{tabular}

illustrates that both the average and effective current values of $\mathrm{M}$-arc show no obvious change after adding the T-arc, while the voltage of $\mathrm{M}$-arc has a remarkable increase and the voltage of $\mathrm{T}$ is also higher than the setting one. Moreover, the standard difference enlarges the agitation of the current and the voltage.

In the experiment both of the two wires are anode. Therefore, serious interference exists due to the electromagnetic force, which results in mutual offset in arc area. The arc length also changes slightly, which further leads to the arc voltage change. This phenomenon can be simply explained by the deviation formula simplification model derived in Figure 4.

The center offset of $\mathrm{M}$ - and L-arcs can be expressed using the following formulas:

$$
\begin{gathered}
l_{\mathrm{T}}=\frac{I_{\mathrm{M}} L_{\mathrm{T}}^{2}}{2 I_{\mathrm{T}} D_{E}}, \\
l_{\mathrm{M}}=\frac{I_{\mathrm{T}} L_{\mathrm{M}}^{2}}{2 I_{\mathrm{M}} D_{E}} .
\end{gathered}
$$

The above offset expressions demonstrate that the offset of one arc is proportional to the other arc's current and the square of its own arc length, while being inversely proportional to its own current and the arc distance. Furthermore, the arc shifts due to the electromagnetic force.

3.2. Analysis of Arc Profile Characteristics of M-Arc. According to the arc image, the arc shape of $\mathrm{M}$ is more stable when it burns alone. The arc dragging effect results in a slight offset towards the opposite direction of welding. As is shown in Figure 5, After T-arc is introduced, the coupled arc stability changes. Due to the attraction between the two arcs, the Marc has a more obvious offset towards T-arc. Using lab view software, the average values of the height, length, and area of $\mathrm{M}$-arc are calculated. In the circumstance of single-wire welding, the width, length, and area of $\mathrm{M}$-arc are $10.23 \mathrm{~mm}$, $5.76 \mathrm{~mm}$, and $39.17 \mathrm{~mm}^{2}$, respectively. After adding T-arc to the system, the coupled arc shape changes into $12.17 \mathrm{~mm}$ in width, $6.73 \mathrm{~mm}$ in length, and $52.09 \mathrm{~mm}^{2}$ in area.

According to the principle of minimum voltage, the energy consumption characterization of arc tends to be minimized and the arc is symmetry in axis when a certain condition of current and boundary is determined. As the arc is in a stable state, the arc column diameter $(D)$ and 


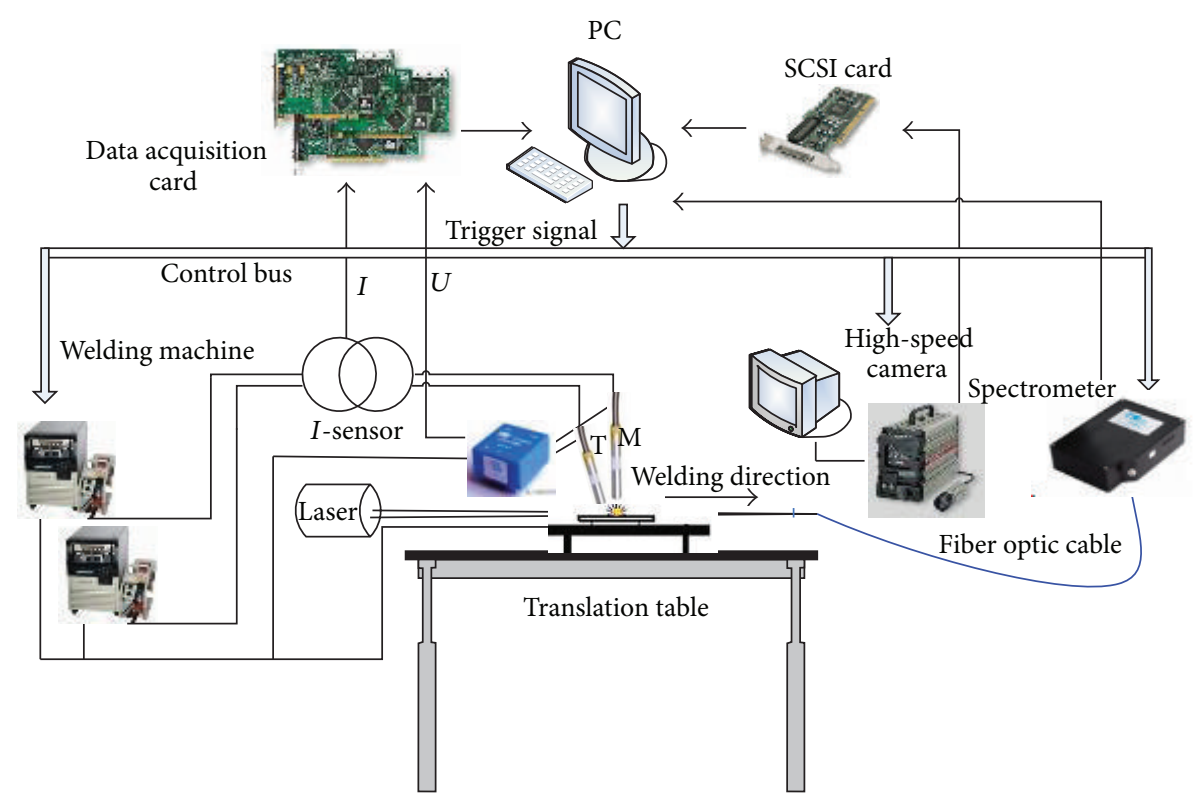

FIGURE 2: Experimental system of high-speed twin wire welding.

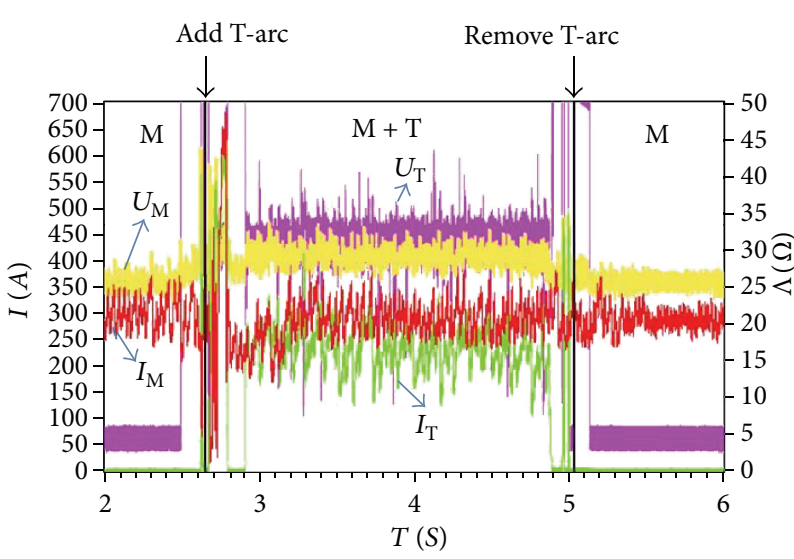

FIGURE 3: Electrical diagram of twin wire of GMAW.

temperature $(T)$ should enable the electric field intensity of arc column $(E)$ to own a minimum value.

When the $\mathrm{T}$-arc approaches to $\mathrm{M}$-arc, it can be considered as the fact that the arc is compelled to be heated by surrounding medium. According to the principle of minimum voltage, the cross-section area of the arc will be automatically increased, leading to the reduction of current density, electric field strength, and electric arc temperature. When the heat dissipation is eliminated, a little heat is produced by the arc for compensation. Therefore, the arc heat production is $I * E$, where current $I$ keeps invariant and $E$ is reduced. According to the principle of minimum voltage, the arc has an automatic dropping tendency to drive $E$ to the minimum value, indicating the heat dissipating capacity reduction to present the maximum tendency. Therefore when the arc is being heated, the arc will automatically expand to a certain diameter, and then arc electric field strength $E$ becomes the maximum reduction.

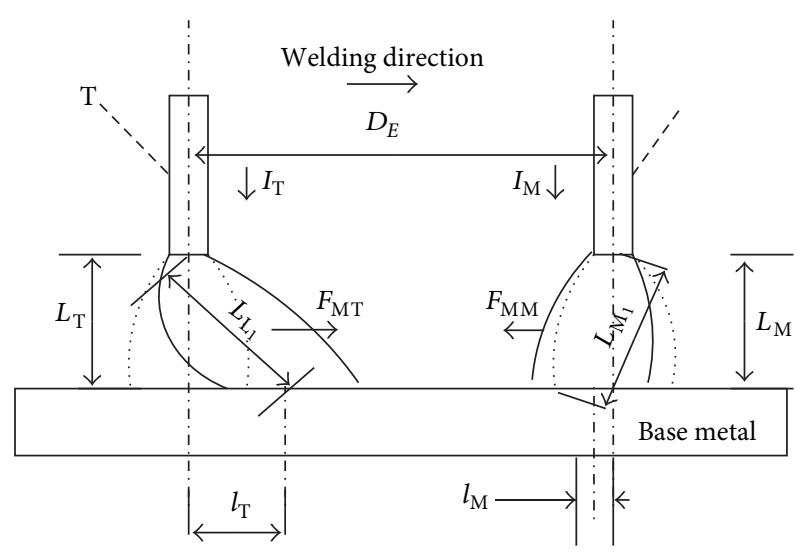

FIGURE 4: Schematic illustration of electromagnetic force acted on $\operatorname{arc}\left(D_{E}\right.$ : the distance between $\mathrm{M}$ - and L-arcs; $I_{\mathrm{M}}, I_{\mathrm{T}}$ : the current of $\mathrm{M}$-arc and T-arc; $L_{\mathrm{M}}, L_{\mathrm{T}}$ : the initial arc length of $\mathrm{M}$-arc and T-arc; $F_{\mathrm{ML}}, F_{\mathrm{MT}}$ : the Lorenz force).

3.3. Analysis of Droplet Transfer and Wire Extension Length of $M$-Arc. During the process of single arc welding, the droplet transfer frequency of $\mathrm{M}$-arc is about $30 \mathrm{HZ}$. After adding Tarc, the droplet transfer frequency of $\mathrm{M}$-arc reaches about $40 \mathrm{HZ}$. When T-arc is added, the droplet transfer mode of Marc as well as the rejection transfer mode remains unchanged. The transfer frequency increases, while the droplet size becomes smaller, as is shown in Figure 6. The fact that no obvious change occurs in the current of M-arc after T-arc is added demonstrates that the wire feeding speed remains unchanged throughout the experiment. It is because welding wire feeding rate determines the current variation. Moreover, due to the heating effect of T-arc welding wire, the melting heat increases, which increases the welding wire melting rate. As wire feeding rate keeps unchanged, the droplet size becomes smaller. 


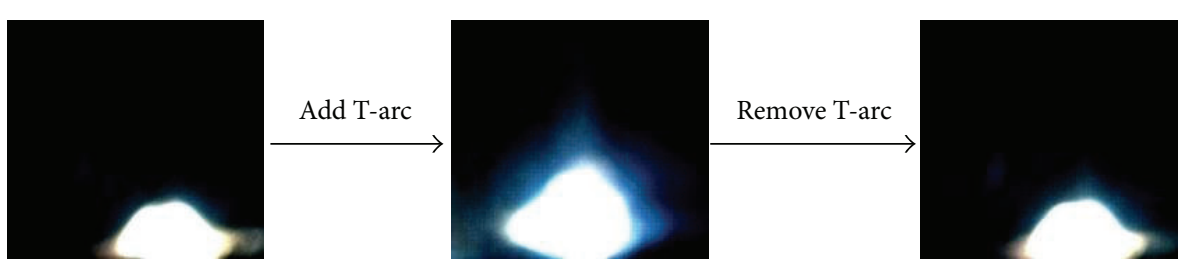

Figure 5: Arc image of M-arc.

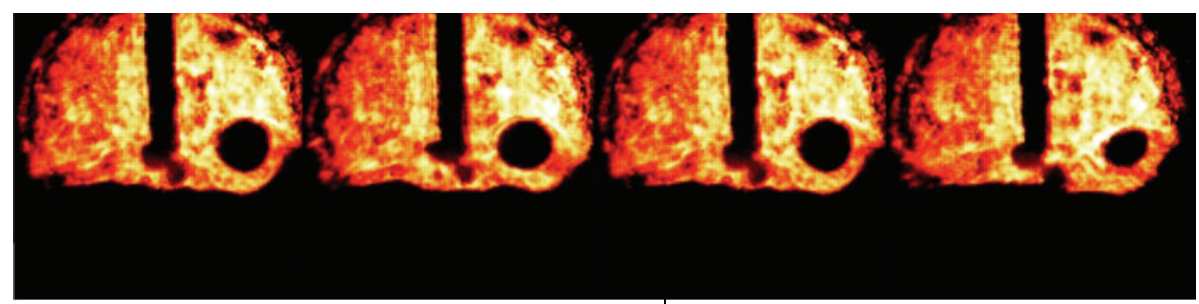

(a) Add T-arc

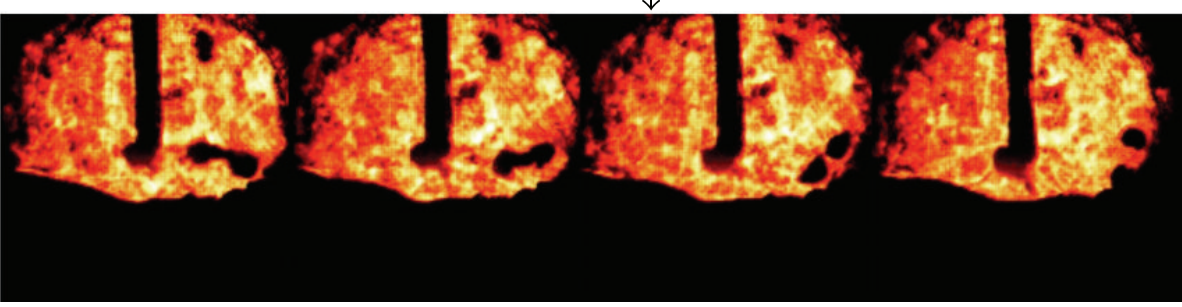

(b)

Figure 6: Droplet transfer of M-arc: (a) droplet transfer of M-arc simplex welding; (b) droplet transfer of M-arc welding after adding T-arc.

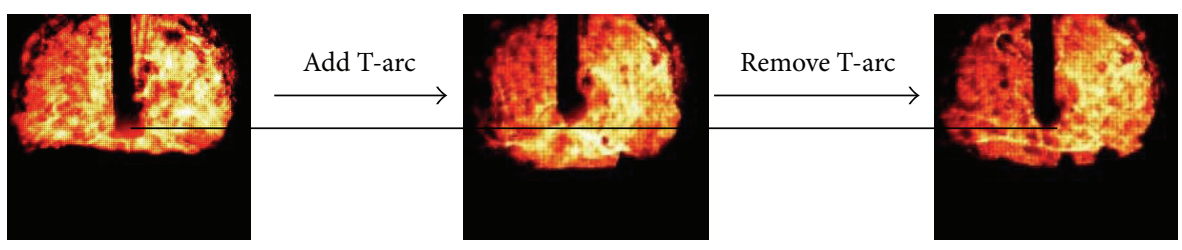

FiguRE 7: Wire extension length of M-arc.

The wire extension length of $\mathrm{M}$-arc is calculated when it is burning alone and after adding T-arc using lab view, respectively. As shown in Figure 7, the wire extension length of $\mathrm{M}$-arc decreases after T-arc is added. Tire extension length changed from $10.16 \mathrm{~mm}$ to $9.92 \mathrm{~mm}$ after T-arc is added under the condition of $I_{\mathrm{M}}=250 \mathrm{~A}$ and $I_{\mathrm{T}}=200 \mathrm{~A}$, respectively.

The decrease of wire extension length can be explained in the wire heating source. Previous researches have widely studied the mechanism of heating in welding process and concluded a similar opinion. The total wire heat $P_{m}$ causing heating and melting consists of two main parts: one is heat production of arc near electrode region and the other is the resistance heat. Tichella et al. [12] point out that the heat for heating and melting of welding wire mainly comes from the energy of the anode to absorb electrons (back), which means that the arc heat is the main energy for melting welding wire, while Lesnewich [13] considers that the resistance heat of wire extension length is the main energy for melting welding wire, even in the case of low welding current. If there are an increase in the wire extension length and a reduction in wire crosssectional area, it also leads to the increase of wire melting speed.

There is no doubt that wire melting heat comes from two parts: arc heat and resistance heat. However, for the twin wire welding being heated by the adjacent-arc, the heat for heating and melting of welding wire should consist of three parts. The expression is as follows:

$$
\begin{aligned}
P_{m} & =P_{A}+P_{R}+P_{L}=I_{a}\left(U_{m}+I_{a} R_{s}\right)+P_{L} \\
& =I_{a}\left(U_{w}+I_{a} \rho \frac{L_{s}}{S}\right)+P_{L}
\end{aligned}
$$


where $P_{m}$ is the total quantity of heat for heating and melting of welding wire; $P_{A}$ is the arc near electrode region heat; $P_{R}$ is the resistance heat; $P_{L}$ is the second arc heat; $I_{a}$ is the welding current; $U_{m}$ is the equivalent voltage of arc melting of welding wire; $U_{w}$ is the work voltage; $R_{s}$ is the wire extension length resistance; $\rho$ is the welding wire resistance; $L_{s}$ is the wire extension length; $S$ is the wire area.

The welding wire is connected to anode; thus the heat for melting welding wire mainly relies on the heat generated by resistance heat in anode area. $U_{m}$ is similar to $U_{w}$ (work voltage), and $U_{w}$ is related to the materials. With a given material, the anode heat production is only related to the current. Due to the adding of welding wire, welding wire is provided with adjacent heat $P_{L}$, while the fuse rate and $P_{m}$ remain unchanged. Since $U_{w}$ and $P_{A}$ keep invariant, $P_{R}$ and $L_{s}$ have a relative decrease. Hence, wire extension length decreases.

\section{Conclusions}

(1) The experimental setup is established in order to study the interference behavior between twin wire arcs including measuring the synchronous signals of current and voltage and observing the arc profile, droplet transfer process, and wire extension length variation.

(2) Because of the presence of arc pressure, the arc length and the voltage increase. The current remains unchanged, while the agitation increases in twin wire welding process.

(3) Due to the effect of arc interaction, twin wire welding droplet transfer frequency increases quickly and the droplet size becomes smaller. At the same time, wire extension length decreases which indicates that the welding point changes.

\section{Acknowledgment}

This research is financially supported by the National Natural Science Foundation of China (Grant no. 51275299).

\section{References}

[1] T. C. Nguyen, D. C. Weckman, D. A. Johnson, and H. W. Kerr, "High speed fusion weld bead defects," Science and Technology of Welding and Joining, vol. 11, no. 6, pp. 618-633, 2006.

[2] A. Hiroshi, M. Tomokazu, and N. Shigeo, "Technical development of advanced 3-electrode MAG high speed horizontal fillet welding process," IIW Doc. No. XII- 1898-06:92.

[3] Y. Ruan, X. M. Qiu, W. B. Gong, D. Q. Sun, and Y. P. Li, "Mechanical properties and microstructures of 6082-T6 joint welded by twin wire metal inert gas arc welding with the $\mathrm{SiO}_{2}$ flux," Materials and Design, vol. 35, pp. 20-24, 2012.

[4] T. Ueyama, T. Ohnawa, M. Tanaka, and K. Nakata, "Occurrence of arc interaction in tandem pulsed gas metal arc welding," Science and Technology of Welding and Joining, vol. 12, no. 6, pp. 523-529, 2007.

[5] D. V. Kiran, B. Basu, A. K. Shah, S. Mishra, and A. De, "Probing influence of welding current on weld quality in two wire tandem submerged arc welding of HSLA steel," Science and Technology of Welding and Joining, vol. 15, no. 2, pp. 111-116, 2010.

[6] R. P. Reis, A. Scotti, J. Norrish, and D. Cuiuri, "Investigation on welding arc interruptions in the presence of magnetic fields: welding current influence," IEEE Transactions on Plasma Science, vol. 40, no. 3, pp. 870-876, 2012.

[7] A. Scotti, C. O. Morais, and L. O. Vilarinho, "The effect of outof-phase pulsing on metal transfer in twin-wire GMA welding at high current level," Welding Journal, vol. 85, no. 10, pp. 225230, 2006.

[8] T. Ueyama and T. Ohnawa, "Occurrence of arc interference and interruption in TANDEM pulsed GMA welding," IIW Doc, No, XII-1883-06.

[9] T. Ueyama, T. Ohnawa, M. Tanaka, and K. Nakata, "Effects of torch configuration and welding current on weld bead formation in high speed tandem pulsed gas metal arc welding of steel sheets," Science and Technology of Welding and Joining, vol. 10, no. 6, pp. 750-759, 2005.

[10] B. Yudodibroto, M. Hermans, and I. Richardson, "Process stability analysis during TANDEM wire arc welding," IIW Doc.XII-1876-06, 2006.

[11] T. Ueyama, T. Ohnawa, T. Uezono, M. Tanaka, M. Ushio, and K. Nakata, "Solution to problems of arc interruption and stable arc length control in TANDEM pulsed GMA welding," Welding International, vol. 20, no. 8, pp. 602-611, 2006.

[12] G. Tichella, G. Jelmorini, and V. Heuvel, "Droplet temperature measurement in arc welding," IlWDoc,212-411-77, 1977.

[13] A. Lesnewich, "Control of melting rate and metal transfer in gas-shielded metal-arc welding part I-Contrlo of electrode melting rate," Welding Journal, no. 8, pp. 343-345, 1958. 

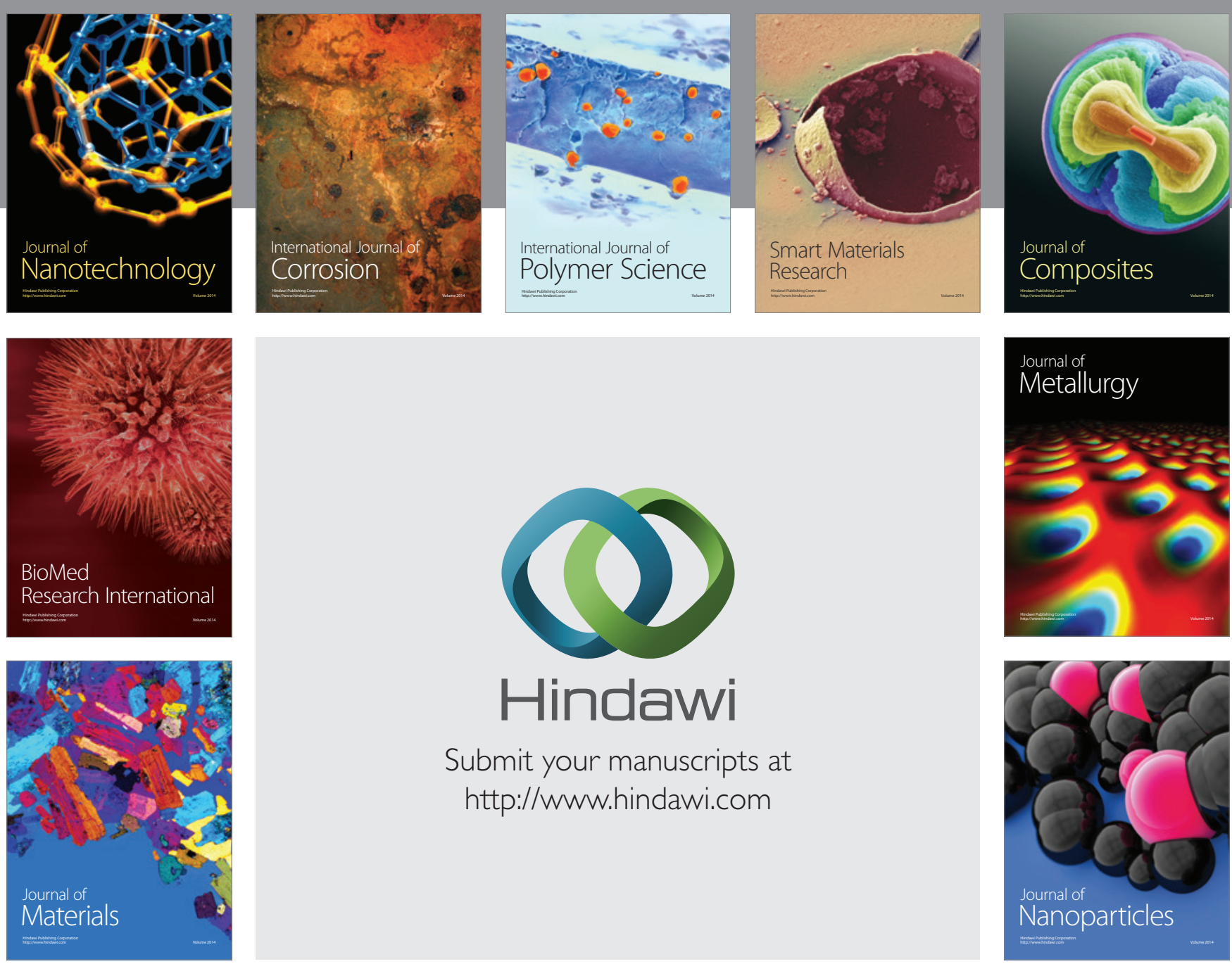

Submit your manuscripts at http://www.hindawi.com
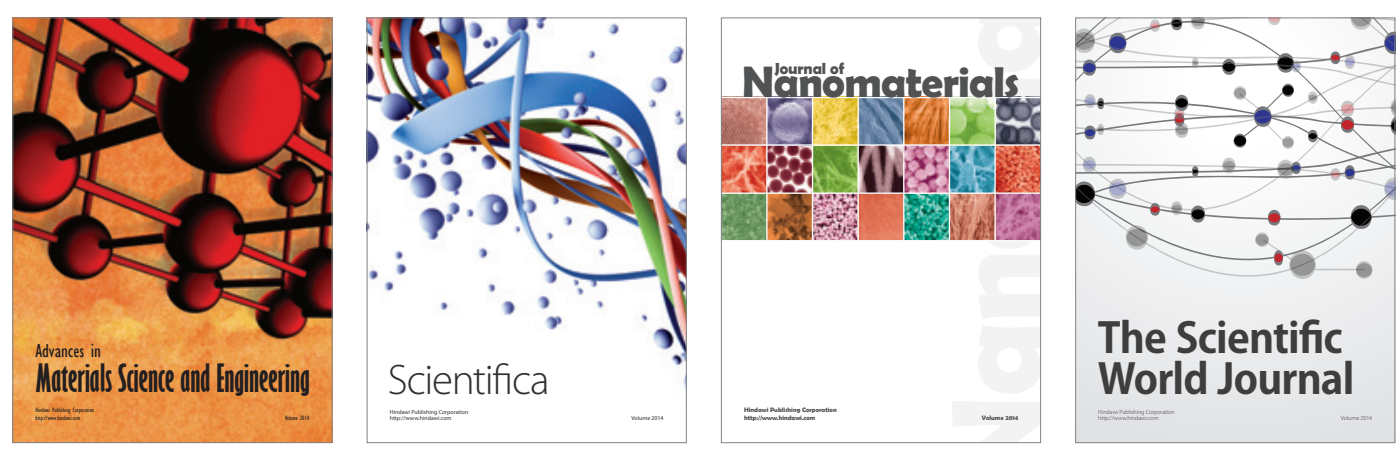

\section{The Scientific World Journal}
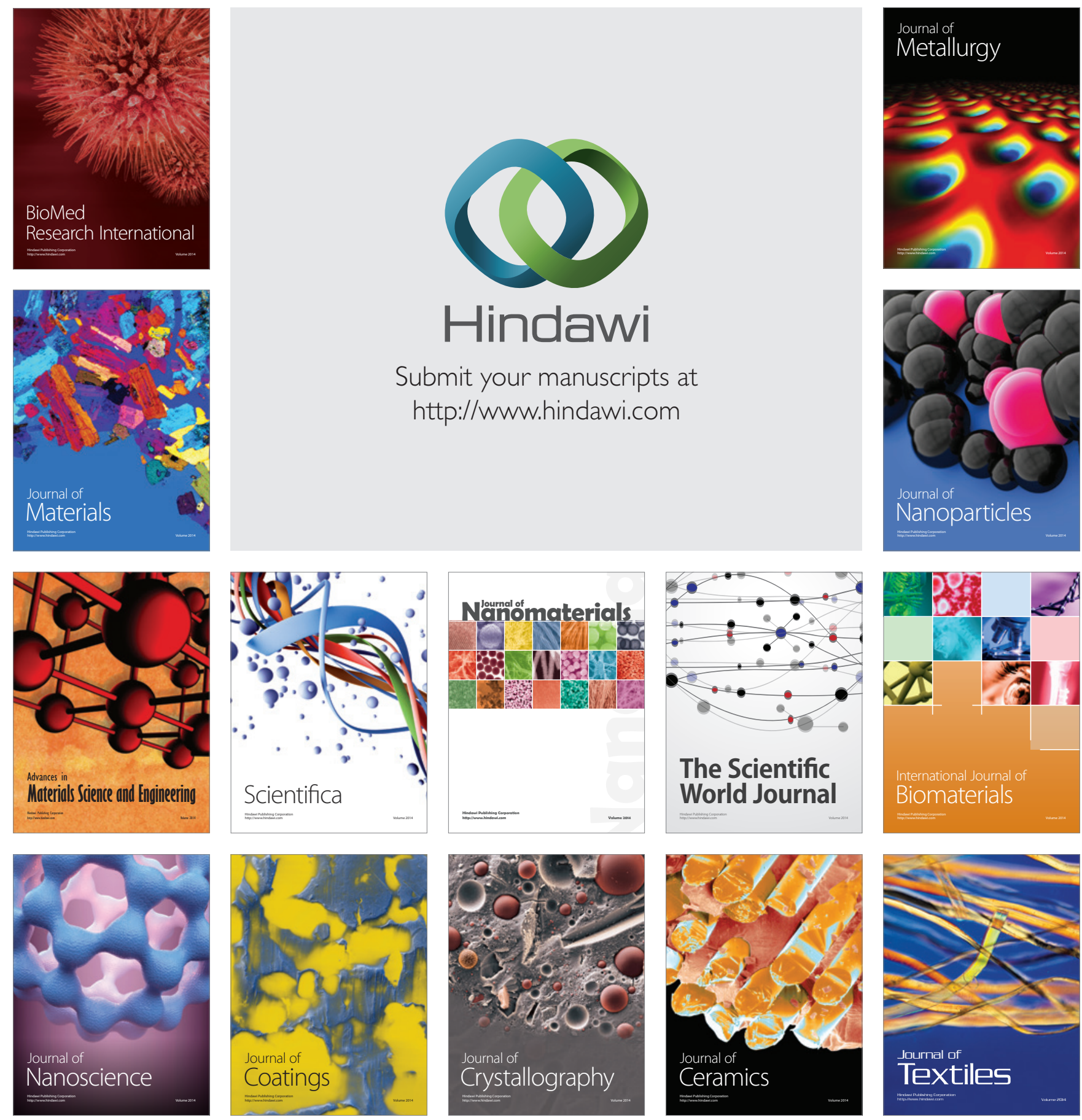